\title{
Nearest neighbour relationships in Pinus yunnanensis var. tenuifolia forests along the Nanpan River, China
}

\author{
Yuanfa Li ${ }^{(1)}$, \\ Gangying Hui (2), \\ Sufang $\mathrm{Yu}^{(1)}$, \\ Yehong Luo ${ }^{(1)}$, \\ Xianyu Yao ${ }^{(1)}$, \\ Shaoming Ye ${ }^{(1)}$
}

Forest stand structural diversity can be examined at different scales. Smallscale structural changes are the basis of forest structural diversity and habitat heterogeneity, and play a key role in biodiversity conservation. Most research on forest structure has focused mainly at stand level and above, with little attention paid to fine-scale structure and correlations among different forest stand attributes. We set up four permanent plots within a secondary forest community of Pinus yunnanensis var. tenuifolia mixed forests along the Nanpan River in southern China. We analyzed their nearest-neighbor relationships using a bivariate distribution of stand spatial structural parameters (SSSP) with the aim of understanding the processes that drive structural diversity in the development of a secondary forest community. Our results revealed that communities with different disturbance histories and species compositions differed in the level of species mixture. Large, small, and medium-sized trees were well mixed within the community, both conspecific and heterospecificindividual with varying densities. All plots exhibited a uniform size differentiation pattern. Trees with different dominance levels or mixture levels were randomly distributed within the plots, and only few of these displayed clumped or regular distribution. Pearson's correlation analysis revealed that distribution patterns may be related to species composition and diameter differentiation, though their relationship was very weak. The results of this study are relevant to optimize forest management activities in the studied stands, and promote tree growth, regeneration and habitat diversity at the fine scale.

Keywords: Bivariate Distribution, Nearest Neighbour Trees, Pinus yunnanensis, Secondary Forest, Structure Diversity

agement (Boncina 2000, Silver et al. 2013). Recently, much attention has been paid to the value of forest ecosystems and the diversified benefits and multiple functions provided by the forest stands. More structured forests can increase their biodiversity and strengthen forest ecosystem services (Li et al. 2016). However, although classic forest management models aimed at improving the forest structural diversity are based on principles drawn from the knowledge of natural ecosystem process (Svebsson \& Jeglum 2001), the resulting management principles are not yet able to meet the forest management needs. Therefore,
(1) College of Forestry, Guangxi University, Daxue East Road 100, Xixiangtang District, Nanning, Guangxi Province 530004 (China); (2) Research Institute of Forestry; Chinese Academy of Forestry, Key Laboratory of Tree Breeding and Cultivation, State Forestry Administration, Box 1958, Beijing 100091 (China)

@ Shaoming Ye (xianggelilalyf@sina.com)

Received: Feb 12, 2017 - Accepted: Jun 04, 2017

Citation: Li Y, Hui G, Yu S, Luo Y, Yao X, Ye S (2017). Nearest neighbour relationships in Pinus yunnanensis var. tenuifolia forests along the Nanpan River, China. iForest 10: 746-753. - doi: 10.3832/ifor2405-010 [online 2017-08-01]

Communicated by: Matteo Garbarino a deeper understanding of forest structural diversity and the differences between forest types is required (Peck et al. 2014).

Forest structural diversity exists at a variety of spatial scales, which can be roughly divided into four levels (in descending order): delta, gamma, beta, and alpha. The delta and gamma levels include landscapescale and large forest areas (Pommerening 2002, Kuuluvainen et al. 2014), comprise all forest community types, and are considered in studies on habitat fragmentation (Kint et al. 2000). The beta level, or medium scale, enables the comparison between forest stands. The alpha level is the smallest scale, and depends on stand-level characteristics. Patch dynamics generally deal with small or very fine scales (Frazer et al. 2005, Getzin et al. 2006, Castaño-Villa et al. 2014). These classifications are directly related to the appearance of the forest community. Many studies have been carried out at landscape and especially stand levels (Boncina 2000, Pommerening 2006, Castaño-Villa et al. 2014, Kuuluvainen et al. 2014). This may be because standlevel data are relatively easy to acquire and interpret, particularly due to the availability of tools and techniques designed for forest management at this scale.

However, as forest management technologies and the knowledge of forest eco- 
system diversity improve, a better understanding of forest structural diversity at smaller scales is increasingly needed, with particular regards of the relationships taking place among nearest neighbour trees and their spatial distribution (Pommerening 2002). This information is important for three major reasons: (i) it allows a better understanding of the processes underlying the forest community succession, including the competition between trees of different sizes (Coomes \& Allen 2007, Potvin \& Dutilleul 2009); (ii) it reveals the cycle of aging and death in dominant tree groups and regeneration and growth from the understory (Muscolo et al. 2014); and (iii) it is related with the chemical and physical intraspecific and interspecific interactions (Chu et al. 2014, Li et al. 2014a). Forest management can exploit these mechanisms to determine the ratio of tree species, control distances between individuals, and plan harvesting and regeneration. It may also help clarify the relationships between forest stand structure and the type and quantity of other organisms living in the forest, particularly those vulnerable to changes in habitat (Vilhar \& Simončič 2012, Janík et al. 2014). To our knowledge, understanding of forest structural diversity at different scales is still incomplete. In particular, little attention has been paid to the spatial relationships of nearest neighbour trees, which could be revealed through an analysis of natural forests of different types and ages.

Pinus yunnanensis var. tenuifolia is a geographical variety of Pinus yunnanensis (Franch.) that has spread down the Nanpan River valley. Historically, its range was the long and narrow area formed by the riverbanks of the Nanpan and Beipan Rivers, as well as the Hongshui River ( $\mathrm{Li} \&$ Wang 1981). $P$. yunnanensis var. tenuifolia is a dominant species influencing the habitats and species composition of the plant community (Wang 1991). Its leaves are thin, tender, and glossy, an adaptation to the dry, hot local climate of these river valleys. Most of the primary $P$. yunnanensis var. tenuifolia forests disappeared after the excessive cutting carried out between 1950 and 2000. The high quality of the wood materials produced by this species induced the Chinese government to protect these forests. Nonetheless, after the completion of the Longtan Dam in the lower reaches of the Hongshui River in 2005, flooding destroyed a large proportion of the P. yunnanensis var. tenuifolia forests. Subsequently, the population redistribution occurred after the flooding resulted in the deforestation of mountain areas for farming and grazing livestock. Only sparse secondary forests of $P$. yunnanensis with different age structures and disturbance histories have remained in Guangxi province (Fig. 1). Since 2006, the remaining forest resources were protected with the establishment of the Yachang Orchid National Nature Reserve. At present, however, we still know very little of the present situation and characteristics of such P. yunnanensis forests. Previous studies were conducted in very limited areas with the aim of examining their geographical distribution before cutting (Fan \& Xue 1993), the community composition (Wang 1991), and soil fertility characteristics (Yang \& Li 1988), as well as to inventory the understory and tree harvest (Anonymous 1960).

As current $P$. yunnanensis var. tenuifolia forests show different tree species compositions and experienced different disturbance type and severity, we hypothesized that their nearest neighbour relationships differed from each other. The aims of this study were to: (1) explore the variation of nearest neighbour relationships between trees along the secondary succession of these forests; (2) analyze the degree of correlation between various stand spatial properties; (3) determine the structural diversity of $P$. yunnanensis var. tenuifolia secondary forests and clarify its dynamics.

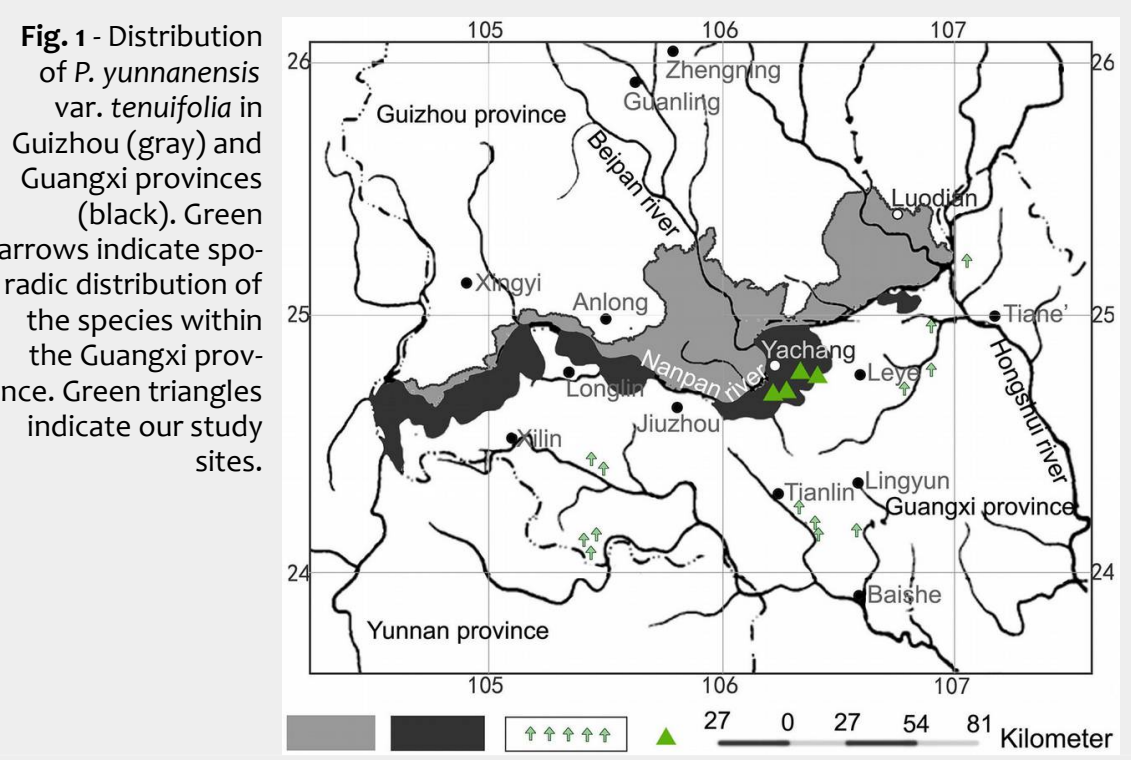

\section{Materials and methods}

\section{Study site}

Our study area was located in the Yachang National Orchid Reserve, Leye, Baise, Guangxi Zhuang Autonomous Region ( $24^{\circ} 44^{\prime} 16^{\prime \prime}-24^{\circ} 53^{\prime} 58^{\prime \prime} \mathrm{N}$; $106^{\circ} 11^{\prime} 31^{\prime \prime}$ $\left.-106^{\circ} 27^{\prime} 04^{\prime \prime} \mathrm{E}\right)$, belonging to the border area of the Yunnan, Guizhou, and Guangxi provinces located in southwest China. It is also the transition zone from the YunnanGuizhou plateau area to the hilly mountains of Guangxi. This reserve is $26.2 \mathrm{~km}$ in length (east-west) and $18 \mathrm{~km}$ in width (north-south), with a total area of 22.062 ha. Its terrain is mainly medium- to low-elevation mountains that trend roughly from northwest to southeast, with many valleys and overlapping peaks. Panguwang Mountain is $1971 \mathrm{~m}$ in elevation, and the lowest point in the valleys is approximately $400 \mathrm{~m}$ a.s.l. The climate is subtropical monsoon, and is strongly influenced by monsoon circulation and foehn effects. A humid (marine) climate prevails in summer, whereas a cold (mainland) climate is typical in winter. The average annual temperature is $16.3^{\circ} \mathrm{C}$, with a maximum temperature of $41.1^{\circ} \mathrm{C}$ and a minimum temperature of $-3^{\circ} \mathrm{C}$, with occasional frost and snow in winter. Rain falls mainly in summer; the average annual rainfall is approximately $1051.7 \mathrm{~mm}$. Significant drought occurs in spring and autumn. In valleys lower than $500 \mathrm{~m}$ a.s.l., cinnamon soil predominates, and at higher altitudes (500-1000 m) hilly red soils are common. Mountain yellow brown soil appears only above $1000 \mathrm{~m}$ in altitude, and develops into meadow soil at the tops of some mountains. This area is known for a great number of wild orchids, including Tiankeng groups, as well as some unique and rare Chinese plants such as the Handeliodendron bodinieri (Levl.) Rehd. and the tree fern Alsophila spinulosa (Wall. ex Hook.) R. M. Tryon.

Our study sites were located at the Huaping, Langquan, and Yigou conservation stations. These are situated in secondary forests in areas where primary $P$. yunnanensis var. tenuifolia forests had been severely damaged. They had experienced different types of disturbance and recovery, resulting in two main types of species composition (Fig. 1). Without human disturbance, the pine-oak mixed forests at Langquan preservation station naturally developed on the burn blank where virgin forest had been completely destroyed at 1987. P. yunnanensis var. tenuifolia and other several oak species dominate the plant community of 18 tree species. Many standing dead trees and fallen logs remain in different stages of decay, and the ground is covered by a thick litter layer. The canopy cover is full and tree density is high, with little vertical structure. The slope of the forest floor is steep, and tree species change notably with increases in altitude, shifting toward oak seedlings. At the Huaping conservation station, pine-Keteleeria mixed forest regen- 
erated following intense thinning in 1970. $P$. yunnanensis var. tenuifolia and Keteleeria davidiana (Bertr.) Beissn. are the dominant species. Plant species richness is very high; in addition to the 40 species of trees and shrubs, there are also six types of climbing plants. K. davidiana and Q. variabilis seedlings are abundant. The pine-oak mixed forests at the Yigou conservation station are dominated by both $P$. yunnanensis var. tenuifolia and Q. variabilis, which regenerated following clear-cuts in 1960 on lands once covered by primary forest. During its recovery period, approximately half of the $P$. yunnanensis var. tenuifolia population on medium slopes were cut for sap in 1990, and some oaks were harvested for fuel; only a few trees were cut on the steeper slopes at higher altitudes. A large number of dead Lyonia ovalifolia var. elliptica, $L$. ovalifolia var. lanceolata, and P. yunnanensis var. tenuifolia remain on the forest floor. The forest features a total of 27 species, 4 varieties of orchids, and a thin litter layer. Although plant species compositions differ between these forests, they share barren, dry, weakly acidic soils with high gravel content. There are few traces of cutting and regeneration in the $P$. yunnanensis var. tenuifolia population (Tab. 1, Tab. 2).

\section{Plot establishment}

During 2015 to 2016, we selected two different types of $P$. yunnanensis var. tenuifolia communities from the conservation stations described, using a typical sampling method (Fig. 2). We used GPS to locate areas large enough for sampling, then used a total station (model NTS-372R10, South Surveying and Mapping Instrument Co.,
Tab. 1 - The main characteristics of $P$. yunnanensis var. tenuifolia communities.

\begin{tabular}{|c|c|c|c|c|}
\hline Parameter & Plot a & Plot b & Plot c & Plot d \\
\hline Site & Daping & Yigou & Hua ping & Yigou \\
\hline Location & $\begin{array}{l}106^{\circ} 19^{\prime} 4.2^{\prime \prime} \mathrm{N}, \\
24^{\circ} 51^{\prime} 15.9^{\prime \prime} \mathrm{E}\end{array}$ & $\begin{array}{l}106^{\circ} 14^{\prime} 14.6^{\prime \prime} \mathrm{N}, \\
24^{\circ} 47^{\prime} 25.4^{\prime \prime} \mathrm{E}\end{array}$ & $\begin{array}{l}106^{\circ} 23^{\prime} 10.6^{\prime \prime} \mathrm{N}, \\
24^{\circ} 49^{\prime} 54.2^{\prime \prime} \mathrm{E}\end{array}$ & $\begin{array}{l}106^{\circ} 14^{\prime} 9.5^{\prime \prime} \mathrm{N}, \\
24^{\circ} 27^{\prime} 28.9^{\prime \prime} \mathrm{E}\end{array}$ \\
\hline $\begin{array}{l}\text { Mean altitude } \\
\text { (m) }\end{array}$ & 1068.5 & 770.3 & 1253.9 & 749.9 \\
\hline Mean slope $\left({ }^{\circ}\right)$ & 26 & 22 & 10 & 25 \\
\hline Slope position & up & up & medium & medium \\
\hline Aspect & Southeast & Southwest & Northwest & Southwest \\
\hline Soil type & rendzina & $\begin{array}{l}\text { mountain yellow } \\
\text { soil }\end{array}$ & rendzina & $\begin{array}{l}\text { mountain yellow } \\
\text { soil }\end{array}$ \\
\hline Gravel content & $40.6 \%$ & $35.4 \%$ & $53.9 \%$ & $38.1 \%$ \\
\hline Community type & $\begin{array}{l}\text { Pine-oak mixed } \\
\text { forest }\end{array}$ & $\begin{array}{l}\text { Pine-oak mixed } \\
\text { forest }\end{array}$ & $\begin{array}{l}\text { Pine-other coni- } \\
\text { fer mixed forest }\end{array}$ & $\begin{array}{l}\text { Pine-oak mixed } \\
\text { forest }\end{array}$ \\
\hline Canopy cover & 0.90 & 0.80 & 0.85 & 0.80 \\
\hline $\begin{array}{l}\text { density (trees } \\
\mathrm{ha}^{-1} \text { ) }\end{array}$ & 2931 & 1592 & 1340 & 1340 \\
\hline Plot area $\left(\mathrm{m}^{2}\right)$ & 10000 & 6400 & 8000 & 5600 \\
\hline $\begin{array}{l}\text { Basal area }\left(m^{2}\right. \\
\left.\mathrm{ha}^{-1}\right)\end{array}$ & 33.39 & 22.55 & 32.88 & 26.26 \\
\hline $\begin{array}{l}\text { Litter thickness } \\
(\mathrm{cm})\end{array}$ & $5.0-7.0$ & $1.0-3.0$ & $3.0-5.0$ & $3.0-5.0$ \\
\hline $\begin{array}{l}\text { Disturbance type } \\
\text { and return time }\end{array}$ & $\begin{array}{l}\text { No human inter- } \\
\text { ference }\end{array}$ & $\begin{array}{l}\text { Little pine resin } \\
\text { harvest } \\
\text { ( } 25 \text { years ago) }\end{array}$ & $\begin{array}{l}\text { Intensive } \\
\text { selection harvest } \\
\text { ( } 35 \text { years ago) }\end{array}$ & $\begin{array}{l}\text { Some pine resin } \\
\text { and oak selec- } \\
\text { tion harvest } \\
\text { ( } 25 \text { years ago) }\end{array}$ \\
\hline $\begin{array}{l}\text { Regeneration } \\
\text { type }\end{array}$ & $\begin{array}{l}\text { Natural, fol- } \\
\text { lowing fire }\end{array}$ & $\begin{array}{l}\text { Natural, fol- } \\
\text { lowing clear-cut }\end{array}$ & $\begin{array}{l}\text { Natural, fol- } \\
\text { lowing harvest }\end{array}$ & $\begin{array}{l}\text { Natural, fol- } \\
\text { lowing clear-cut }\end{array}$ \\
\hline
\end{tabular}

Guangzhou, China) to divide each area into several subplots $(20 \times 20 \mathrm{~m}$ each $)$ to reduce measurement errors and ensure that closure error for the area was limited to $1 / 400$. We located the precise position in three dimensions of any tree with a diameter at breast height $>5 \mathrm{~cm}$, and marked the tree with a unique identifier. We also recorded tree characteristics such as tree species, height, crown shape, canopy area, and

health status. A total of four plots measuring $100 \times 100 \mathrm{~m}, 100 \times 80 \mathrm{~m}, 80 \times 80 \mathrm{~m}$, and $80 \times 70 \mathrm{~m}$ were established (Fig. 2).

Data analysis

In this paper, we define fine-scale forest structure as the level at which the nearest neighbors can affect each other. We focus on three aspects: tree species composition, diameter differentiation, and distribution

Tab. 2 - The main floristic composition of the four studied plots (a-d).

\begin{tabular}{|c|c|c|c|}
\hline Trees & Shrubs & Herbs & Vines \\
\hline $\begin{array}{l}\text { Albizia kalkora (Roxb.) Prain } \\
\text { Betula alnoides Buch-Ham. } \\
\text { Cyclobalanopsis glauca (Thunb.) } \\
\text { Oerst. } \\
\text { Cyclobalanopsis glaucoides Schottky } \\
\text { Diospyros kaki Thunb. var. silvestris } \\
\text { Makino } \\
\text { Kalopanax septemlobus (Thunb.) } \\
\text { Koidz. } \\
\text { Keteleeria davidiana (Bertr.) Beissn. } \\
\text { Liquidambar formosana Hance } \\
\text { Meliosma veitchiorum Hemsl. } \\
\text { Phyllanthus emblica L. } \\
\text { Pinus yunnanensis var. tenuifolia } \\
\text { Quercus variabilis Bl. } \\
\text { Rhus chinensis Mill. } \\
\text { Schima wallichii (DC.) Choisy } \\
\text { Toona ciliata M. Roem. } \\
\text { Vernicia fordii (Hemsl.) Airy-Shaw } \\
\text { Wendlandia uvariifolia Hance }\end{array}$ & $\begin{array}{l}\text { llex crenata Thunb. } \\
\text { Buddleja officinalis Maxim. } \\
\text { Cerasus yedoensis (Matsum.) Yu et } \\
\text { Li } \\
\text { Coriaria nepalensis Wall. } \\
\text { Eurya japonica Thunb } \\
\text { Eurya distichophylla Hemsl. } \\
\text { Glochidion eriocarpum Champ. ex } \\
\text { Benth. } \\
\text { Glochidion puberum (L.) Hutch. } \\
\text { Lespedeza Formosa (Vog.) Koehne } \\
\text { Lyonia ovalifolia (Wall.) Drude var. } \\
\text { elliptica } \\
\text { Lyonia ovalifolia (Wall.) Drude var. } \\
\text { lanceolata (Wall.) Hand.-Mazz. } \\
\text { Mahonia fortunei (Lindl.) Fedde } \\
\text { Myrica rubra (Lour.) S. et Zucc. } \\
\text { Pyrus calleryanar Decne. } \\
\text { Rhus sylvestris Sieb. \& Zucc } \\
\text { Sapium discolor (Champ. ex Benth.) } \\
\text { Muell.-Arg. } \\
\text { Trachycarpus fortunei (Hook.) H. } \\
\text { Wendl. }\end{array}$ & $\begin{array}{l}\text { Asplenium trichomanes L. Sp. } \\
\text { Cleisostoma } \\
\text { fuerstenbergianum Kraenzl. } \\
\text { Cyclosorus acuminatus } \\
\text { (Houtt.) Nakai } \\
\text { Cymbidium ensifolium (L.) Sw. } \\
\text { Dendrobium officinale Kimura } \\
\text { \& Migo } \\
\text { Dicranopteris linearis } \\
\text { (Burm.f.) Underw. } \\
\text { Miscanthus floridulu (Labnll.) } \\
\text { Warb } \\
\text { Monotropa uniflora Linn. } \\
\text { Pteridium aquilinum var. } \\
\text { latiusculum (Desv.) Underw. } \\
\text { ex Heller } \\
\text { Vanda concolor Bl. } \\
\text { Woodwardia japonica (L. f.) } \\
\text { Sm. }\end{array}$ & $\begin{array}{l}\text { Ficus tikoua Bur. } \\
\text { Gynostemma pentaphyllum } \\
\text { (Thunb.) Makino } \\
\text { Lonicea confusa (Sweet) DC. } \\
\text { Parthenocissus tricuspidata } \\
\text { (Siebold \& Zucc.) Planch. } \\
\text { Rubus feddei H. Lév. \& Vaniot }\end{array}$ \\
\hline
\end{tabular}



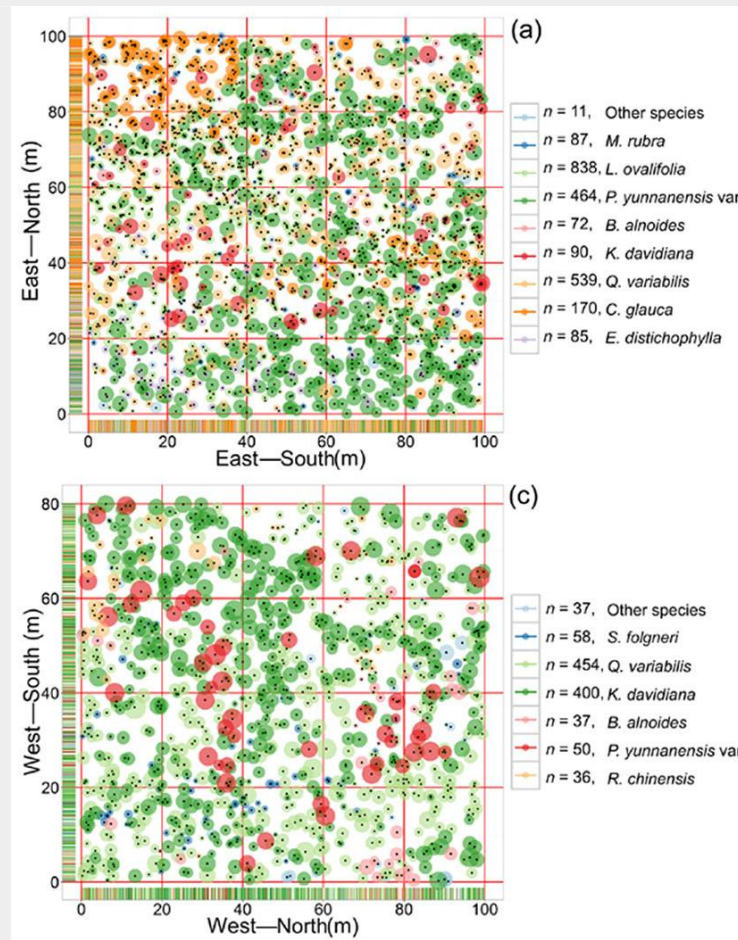
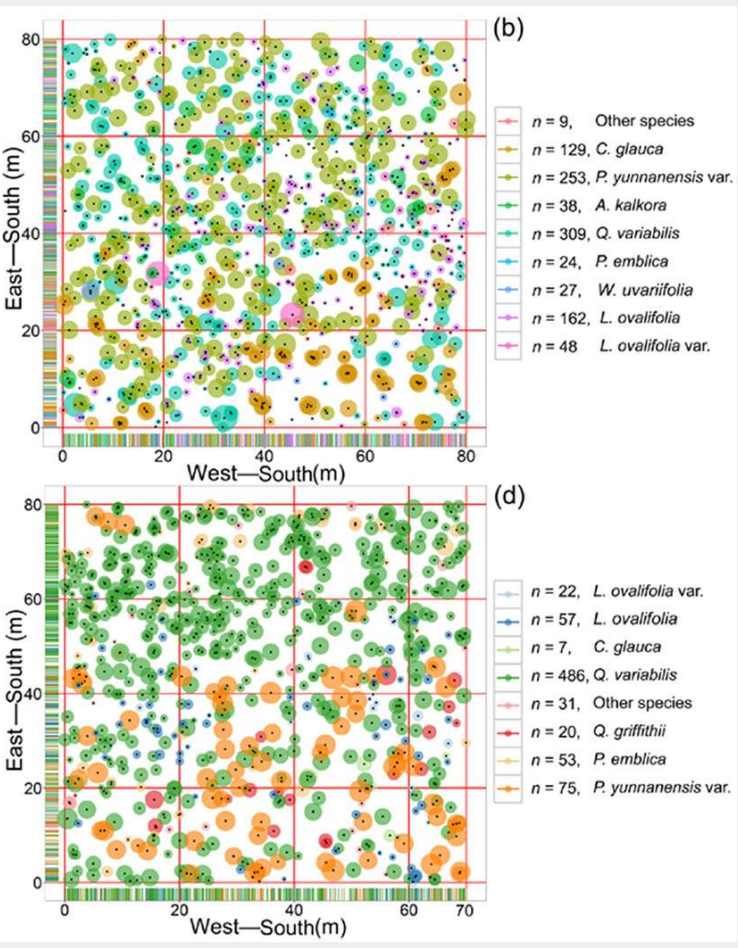

Fig. 2 - Distribution patterns in the four studied plots. Colors of circles indicate tree species and their sizes indicate the diameter. (n): number of tree for each species. pattern; and adopted a group of stand spatial parameters to analyze them: mingling $(M)$, dominance $(U)$, and uniform angle index $(W)$. The parameters $M$ (eqn. 1) and $U$ (eqn. 2) may be regarded as modified versions of Gadow's mixture and the $T$ index (Hui \& Gadow 2003), respectively. They accurately describe tree species segregation and size differentiation ( $L i$ et al. 2012, Ni et al. 2014). Mingling $(M)$ describes the probability of a reference tree $i$ and its

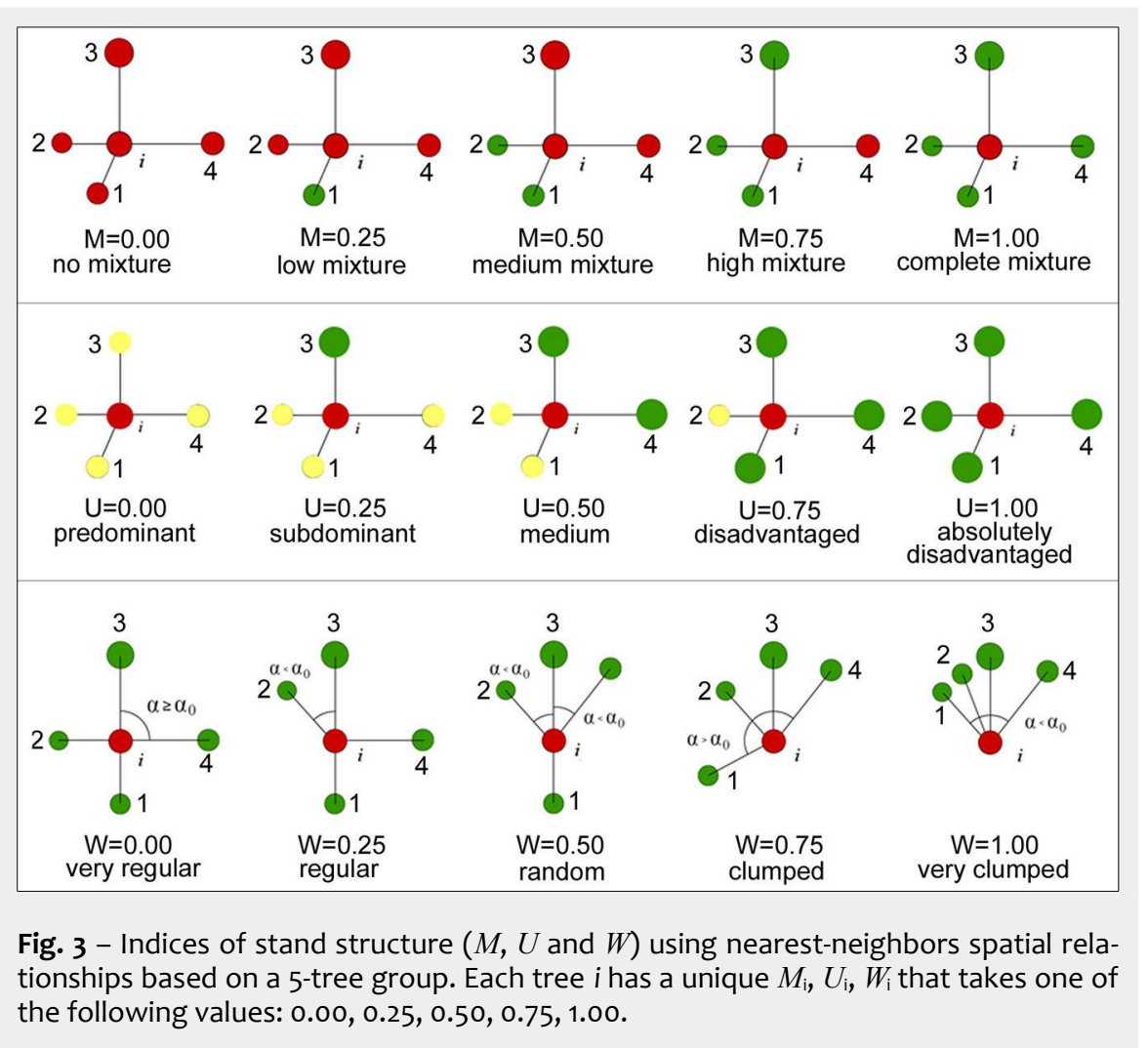

Fig. 3 - Indices of stand structure $(M, U$ and $W)$ using nearest-neighbors spatial relationships based on a 5 -tree group. Each tree $i$ has a unique $M_{\mathrm{i}}, U_{\mathrm{i}}, W_{\mathrm{i}}$ that takes one of the following values: $0.00,0.25,0.50,0.75,1.00$.

four nearest neighbors belonging to the same species; its mean value ranges from 0 to 1 , with higher values indicating higher levels of species mixture (Fig. 3). Dominance $(U)$ describes the comparative sizes of a reference tree $i$ and its four nearest neighbors. Its value ranges from 0 to 1 , with higher values indicating taller trees in a given unit (Fig. 3). The uniform angle index $W$ (eqn. 3) describes the degree of scatter in the four nearest neighbors to a reference tree $i$. Its distribution pattern can be evaluated by comparing the angle formed between any two neighbor trees and the reference tree with a standard angle $\left(a_{0}=72^{\circ}\right)$. Its value ranges from 0 to 1 , with greater values indicating more clustering (Wehenkel et al. 2015, Hui et al. 2016 Fig. 3). Mean $W$ values in the interval 0.4750.517 imply a random distribution pattern. Otherwise, the distribution pattern is clumped (mean $W>0.517$ ) or regular (mean $W<0.475$, Hui et al. 2016 - eqn, 1, eqn. 2 , eqn. 3 ):

$$
\begin{array}{ll}
M_{i}=\frac{1}{4} \sum_{j=1}^{4} v_{i j}, & v_{i j}= \begin{cases}1 & \text { if } s p_{j} \neq s p_{i} \\
0 & \text { otherwise }\end{cases} \\
U_{i}=\frac{1}{4} \sum_{j=1}^{4} k_{i j}, & k_{i j}= \begin{cases}1 & \text { if } d_{j}<d_{i} \\
0 & \text { otherwise }\end{cases} \\
W_{i}=\frac{1}{4} \sum_{j=1}^{4} z_{i j}, & z_{i j}= \begin{cases}1 & \text { if } \alpha_{j}<\alpha_{0} \\
0 & \text { otherwise }\end{cases}
\end{array}
$$

When calculating the $M_{\mathrm{i}}, U_{\mathrm{i}}$ and $W_{\mathrm{i}}$ for each tree, we used the nearest neighbor edge-correction conception (NNS1) to eliminate edge effects (Pommerening \& Stoyan 2006). Each tree has a unique $M_{\mathrm{i}}, U_{\mathrm{i}}$ and $W_{\mathrm{i}}$ that takes values of $0.00,0.25,0.50,0.75$ and 1.00 (Fig. 3). Therefore, for the whole plot, $M, U$ and $W$ meet the requirement of two discrete variable joint in pairs (Sheng et al. 2010). Three permutations can be obtained by joining the three parameters each other, that is, the $M-U, M-W$ and $U-W$ bivariate distributions. Each distribution contains $5 \times 25$ combinations. They have much greater power to detect the spatial characteristics of adjacent trees, compared with univariate analysis. Their ability to provide effective information is far superior to most traditional indices ( $\mathrm{Li}$ et al. 2012, 
2014b). We adopted this modified method to analyze the nearest neighbor relationships in our four plots. Moreover, we applied the Bonferroni's correction (Wehenkel et al. 2015) when analyzing the Pearson's correlation of different levels of the same factor, e.g., in Fig. 4 a the correlation between none mixture $(M=0.00)$ and low mixture axes $(M=0.25)$. The modified critical $P$ value $(\alpha=0.005)$ was calculated by dividing the critical $P$ value (here the significance level $=0.05$ ) by the number of comparison [n (n-1)/2 = 5]. All the calculations were performed in $\mathrm{R} 3.22$ ( $R$ code provided by Dr. Zhang Gongqiao and colleagues see Box 1 in Supplementary material), and figures were prepared using the "corrplot" package. Parts of the results of the correlation analysis are reported in the Supplementary material (Fig. S1 - Fig. S6).

\section{Results}

\section{M-U bivariate distribution}

The individual trees sampled in the four studied plots were spread over all combinations of the $M-U$ bivariate distribution, but with different overall patterns (Fig. 4). In plot d, most trees were concentrated on the low-mixture axis $(M=0.00)$ and few trees on the medium-mixture axis ( $M=$ 0.50 ). In contrast, in plots $a, b$, and c, very few trees were located on the low-mixture axis while most appeared on the mediummixture axis. For the same degree of mixture, the number of trees with different $U$ values was different. The correlation coefficients for $M$ were low in magnitude and there was no significant correlation $(p>$ 0.005 - Fig. S1 in Supplementary material). The number of trees on each $U$ axis $(U=$ 0.00-1.00) was similar and was about $1 / 5$ of the total number of trees in the plot. On the same $U$ axis, however, the number of trees with different $M$ values differed considerably and had only a weak and not significant correlation ( $p>0.005-$ Fig. S2 in Supplementary material).

\section{M-W bivariate distribution}

The $M-W$ bivariate distribution of each plot displayed similar overall characteristics (Fig. 5). Trees populated each $M$ axis ( $M=$ 0.00-1.00), and the number of tree on each $M$ axis first increased, then decreased as $W$ increased. Within the same plot, however, the ranges of change were different, some showed a close correlation ( $p<0.005-$ Fig. $\mathrm{S}_{3}$ in Supplementary material), while others differed from each other $(p>0.005$, Fig. S3). Among all $W$ axes ( $W=0.00-1.00)$, most of the individuals in each plot were located on the random distribution axis ( $W$ $=0.50$ ). The number of trees falling into the axes $W=0.25$ and $W=0.75$ were similar and then decreased. The uniform distribution axis $(W=0.00)$ and clump distribution axis $(W=1.00)$ had the lowest numbers, approaching zero. Their average values were $W_{\mathrm{a}}=0.530, W_{\mathrm{b}}=0.506, W_{\mathrm{c}}=0.489$, and $W_{\mathrm{d}}=0.491$, respectively. The correla-
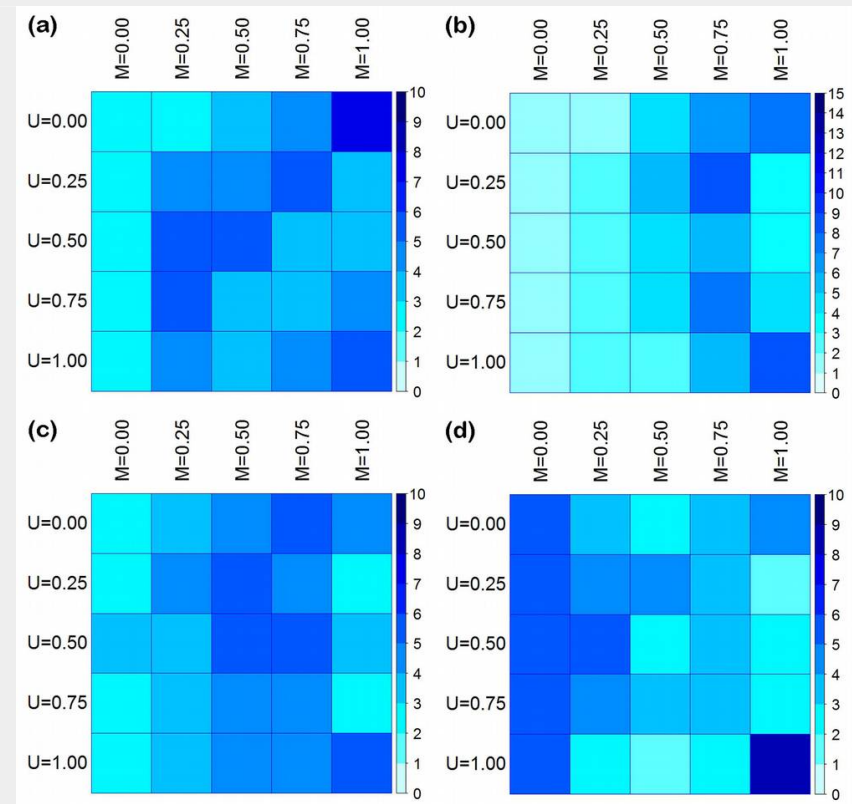

Fig. 4 - The joint distribution (\%) of mingling $(M)$ and dominance $(U)$ in the four measured plots (a, b, c, d). The intensity of color is proportional to the number of trees

falling into each combination (the darker the color, the higher the number).
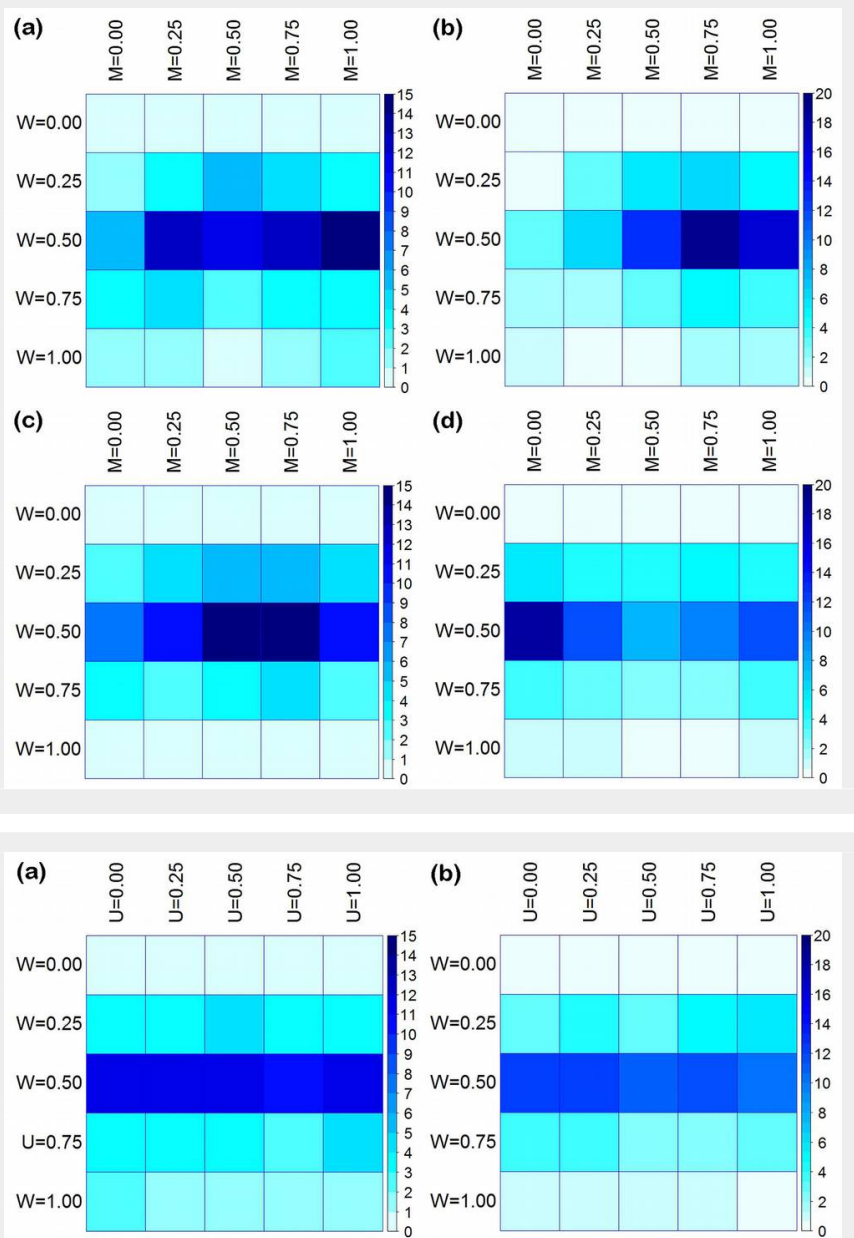

Fig. 5 - The joint distribution (\%) of mingling $(M)$ and uniform angle index $(W)$ in the four measured plots (a, b, c, d).

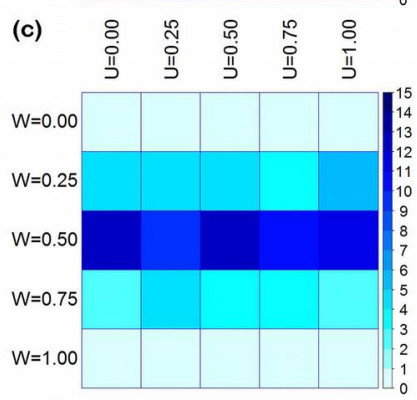
tribution (\%) of dominance $(U)$ and uniform angle index $(W)$ in the four measured plots (a, b, c, d).
Fig. 6 - The joint dis- 
tions for the four plots were very weak ( $p>$ 0.005 - Fig. S4 in Supplementary material).

\section{U-W bivariate distribution}

The $U-W$ bivariate distribution for the four measured plots also exhibited a high degree of similarity and symmetry (Fig. 6), as did the $M-W$ bivariate distribution. The number of individuals on each $U$ axis $(U=$ 0.00-1.00) was similar to a normal distribution, i.e., the value increased and then decreased with increasing $W$ values. Within the same plot, each $U$ axis contained similar numbers of individuals. Their correlation coefficients were high and the correlation was significant ( $p<0.005$ - Fig. S5 in Supplementary material) except some of them in plot $b$. There was a significant difference in the numbers of trees between different $W$ axes ( $\mathrm{W}=0.00-1.00)$. Among these, the random distribution axis ( $W=0.50$ ) contained most trees, followed by the regular distribution axis ( $W=0.25)$ and the partial clump distribution axis $(W=0.75)$. The regular distribution axis $(W=0.00)$ and the clump distribution axis $(W=1.00)$ contained the fewest trees. The correlation coefficient among different $W$ axes was weak and not significant ( $p>0.005$ - Fig. S6 in Supplementary material).

\section{Discussion}

With the acceleration of deforestation, habitat fragmentation and biodiversity loss have become topics of frequent discussion worldwide (Adekunle \& Olagoke 2008). Generally, forest tree diversity is investigated only in terms of species abundance and percent composition, and less attention is paid to the physical spatial structure of the forest community. In fact, different individual trees in three-dimensional space constitute the frame that supports ecosystem diversity and can change within time and space. Changes in spatial structure at fine scales determine the complexity of the forest stand and affect key processes related to tree canopies and the diversity of habitat space and species (Frazer et al. 2005, Castaño-Villa et al. 2014). Fine-scale heterogeneity is particularly important when forest ecosystems face anthropogenic disturbance, and may help improve the ability of ecosystems to resist disasters and to recover after a severe disturbance (Franklin et al. 2007, Churchill et al. 2013). It is impossible to maintain environmental and ecological conditions promoting biodiversity if we neglect the detailed spatial characteristics of the forest (Baskent \& Keles 2005). Although some researchers hold different concept on the scale of small-scale forest structure (Castaño-Villa et al. 2014 vs. Tuten et al. 2015), studies are increasingly focusing on space-time dynamics at this level (Janda et al. 2014, Kuuluvainen et al. 2014).

In this study, plots a and $\mathrm{c}$ were stands of moderately mixed composition, plot $b$ had greater diversity, and plot $\mathrm{d}$ had a relative low mingling value (Fig. 4, Fig. 5). Regard- less of the size of the trees, these plots always maintained similar mingling values. The reference trees had both conspecific and heterospecific neighbors, but the ratios of these differed between plots (Fig. 4). Tree size differentiation was very uniform. Trees of different sizes or neighbors were randomly distributed over all; some exhibited clumped or regular distribution (Fig. 5, Fig. 6). A significant correlation was detected among more than trees with different types of neighbors (Fig. $\mathrm{S}_{3}$ in Supplementary material) and different dominance levels (Fig. S5), suggesting that the distribution pattern associated with species mingling and size differentiation. However, the distribution pattern was rarely influenced by neighboring species or size differentiation (Fig. S4, Fig. S6 in Supplementary material). Additionally, the relationship between size differentiation and neighboring species was very weak (Fig. S1, Fig. S2 in Supplementary material).

The nearest neighbor relationships of the P. yunnanensis var. tenuifolia may be related to species composition, the number or proportion of each species or their distribution pattern within the plot. Each community was rich in tree species, but they differed from each other in species composition. A small number of tree species accounted for a large part of the total number of trees (Tab. 2). For example, $L$. ovalifolia, Q. variabilis, and P. yunnanensis var.tenuifolia accounted for $78.14 \%$ of the total number of trees in plot a; K. davidiana and Q. variabilis accounted for $79.66 \%$ of the trees in plot c; Q. variabilis accounted for $63.86 \%$ of the trees in plot d; and P. yunnanensis var. tenuifolia and Q. variabilis accounted for $55.15 \%$ of the trees in plot b. Abundant species such as L. ovalifolia resulted in crowded plots (Fig. 2), which greatly reduced the degree of segregation. These characteristics are consistent with the modeling results obtained by Graz (2004) and the phenomena detected in natural Scots pine (Pinus sylvestris L.) forests (Kint 2005), i.e., a single tree species with a large number of individuals will reduce the overall degree of mixture.

The nearest neighbor relationships of $P$. yunnanensis var. tenuifolia communities may be related to the length of development across species (Tab. 1). With the exception of plot a which showed a partialregular distribution $\left(W_{\mathrm{a}}>0.517\right)$, the other plots studied (b-d) showed random patterns of horizontal distribution. The transition from clump to random distribution observed in secondary communities matches the expectations based on forest succession laws ( $\mathrm{Li}$ et al. 2014a). At the same time, we observed three levels of species mingling (low, medium, and high) in our four plots, suggesting that the distribution pattern reaches its climax earlier than stands with higher levels of mingling during the entire succession process. To form a highly mixed state, a forest community should include enough tree species with a scattered distribution (Graz 2004). The transition from a pioneer community (composed of $P$. yunnanensis var. tenuifolia, $Q$. variabilis, and L. ovalifolia) to the secondary forest (including several shade-tolerant species like T. ciliata, E. distichophylla, M. rubra, and S. superba) is a long process lasting for decades. Despite the distribution patterns of pioneer and shade-tolerant species are very close to those of primary or long-undisturbed forests, the isolation of tree species in our study is still limited (Janda et al. 2014, Petritan et al. 2015, Svebsson \& Jeglum 2001). Similar results have also been reported for other forests (Takashi et al. 2003, Li 2008, Zhao et al. 2009). Furthermore, Kint (2005) pointed out that species mixing was constantly changing in aging Scots pine forests in European temperate areas, while species mingling was steadily increasing across the whole community. Based on the above evidence, it appears that the continual increase of species mixing in natural forests is a natural phenomenon; whether it will stop and at what level has not yet been elucidated.

Unlike species mixture, size differentiation can occur in the early stages of succession and is related to the distribution pattern (Potvin \& Dutilleul 2009). Tree distribution pattern deeply affect the spatial resources available for each individual tree, strongly influencing its growth (Kint et al. 2003). Consistently with these perspective, trees diameter differentiation in our four plots showed high consistency, considering their distribution patterns (Fig. 6, Fig. S5 in Supplementary material). Getzin et al. (2006) further argued that distribution patterns were related to tree size and were simultaneously influenced by competition. The result of competition between nearest neighbors must lead to changes in size differentiation, death, and new distribution patterns. This could explain the diameter differentiation and random distribution patterns observed in the $P$. yunnanensis var. tenuifolia community. After 40 years since protection of these reforestated areas was established, trees with different dominance levels in Korean pine-broadleaf forests show very similar quantities and distribution patterns ( Li et al. 2012). Individuals of different ages in natural secondary oak forests with large numbers of pioneer species have been shown to have obvious similarity in distribution patterns ( $L i$ 2008). These studies found that diameter differentiation and random distribution patterns are indicative of early successional stages. However, in this study we did not examine the order of uniform size differentiation or the random distribution pattern. More detailed study is required on the different succession stages in this context.

\section{Conclusions}

In forest management, the structure and development dynamics of aging forests are usually an important reference for forest restoration and its promotion toward a 
greater complexity. However, reference primary forests are very rare nowadays; most forests are secondary and established on sites where the native forests suffered from severe disturbances. Therefore, understanding the structural diversity of secondary forests with different characteristics and development stage is of great importance in forest management.

We used the bivariate distribution of SSSP to analyze the nearest-neighbor relationships of $P$. yunnanensis var. tenuifolia secondary forests along the Nanpan River. Our results revealed similarities and differences in spatial structure and tree species composition among different development stages of these forests. We also examined the spatial correlation of size differentiation, species mixture, and distribution patterns of $P$. yunnanensis var. tenuifolia secondary forests, aimed to reveal the ecological processes driving the structural development. The results of this study are an important contribution to forest management optimization, providing a reference in terms of species mixture, distribution patterns and size differentiation, to be pursued for further promoting tree growth, regeneration, and habitat diversity at the fine scale in the studied forest communities.

\section{List of abbreviations}

SSSP: Stand spatial structural parameters; $M$ : mingling; $U$ : dominance; $W$ : uniform angle index; NNS1: nearest neighbor edgecorrection conception.

\section{Acknowledgements}

We thank Li Fengting, Lan Huangxu, Cai Xiaoqing, Long Jiafeng, Pan Ting, Lu Zijin, Tang Wenyan, Zhu Deyi from Guangxi University for providing help in data collection. This paper was financially supported by the National Science Foundation of China (grant no. 31400542), Guangxi Natural Science Foundation (grant 2016GXNSFBA380 233) through the project "Structure characteristics of Pinus yunnanensis var. tenuifolia and its influence on litter (2016-2019)".

\section{References}

Adekunle VAJ, Olagoke AO (2008). Diversity and biovolume of tree species in natural forest ecosystem in the bitumen-producing area of Ondo State, Nigeria: a baseline study. Biodiversity and Conservation 17: 2735-2755. - doi: 10.1007/s1 0531-007-9279-y

Anonymous (1960). Preliminary studies on regeneration and final felling of Pinus yunnanensis Franchet (Guangxi Zhuang Autonomous Region Forestry Research Institute, Guangxi Baise forestry experimental station, Lingle subbureau attached to Guangxi forest industry bureau, Guangxi Lingle forestry farm eds). Scientia Silvae Sinicae 1: 44-54.

Baskent EZ, Keles S (2005). Spatial forest planning: a review. Ecological Modelling 188: 145173. - doi: 10.1016/j.ecolmodel.2005.01.059

Boncina A (2000). Comparison of structure and biodiversity in the Rajhenav virgin forest rem- nant and managed forest in the Dinaric region of Slovenia. Global Ecology and Biogeography 9: 201-211. - doi: 10.1046/j.1365-2699.2000.0015 $5 . x$

Castaño-Villa GJ, Ramos-Valencia SA, Fontúrbel FE (2014). Fine-scale habitat structure complexity determines insectivorous bird diversity in a tropical forest. Acta Oecologica 61: 19-23. - doi: 10.1016/j.actao.2014.10.002

Chu C, Mortimer PE, Wang H, Wang Y, Liu X, Yu S (2014). Allelopathic effects of Eucalyptus on native and introduced tree species. Forest Ecology and Management 323: 79-84. - doi: 10.1016/ j.foreco.2014.03.004

Churchill DJ, Larson AJ, Dahlgreen MC, Franklin JF, Hessburg PF, Lutz JA (2013). Restoring forest resilience: from reference spatial patterns to silvicultural prescriptions and monitoring. Forest Ecology and Management 291: 442-457. doi: 10.1016/j.foreco.2012.11.007

Coomes DA, Allen RB (2007). Effects of size, competition and altitude on tree growth. Journal of Ecology 95: 1084-1097. - doi: 10.1111/j.13652745.2007.01280.x

Fan G, Xue J (1993). Distributional characteristics of Pinus L. in southeast Yunnan. Guihaia 13: 349354.

Franklin JF, Mitchell RJ, Palik B (2007). Natural disturbance and stand development principles for ecological forestry. General Technical Report NRS-19, Northern Research Station, USDA Forest Service, DE, USA, pp. 44. [online] URL: http://www.nrs.fs.fed.us/pubs/gtr/gtr_nrs19.pd $f$

Frazer GW, Wulder MA, Niemann KO (2005). Simulation and quantification of the fine-scale spatial pattern and heterogeneity of forest canopy structure: a lacunarity-based method designed for analysis of continuous canopy heights. Forest Ecology and Management 214: 65-90. - doi: 10.1016/j.foreco.2005.03.056

Getzin S, Dean C, He F, Trofymow J, Wiegand K, Wiegand T (2006). Spatial patterns and competition of tree species in a Douglas-fir chronosequence on Vancouver Island. Ecography 29: 671-682. - doi: 10.1111/j.2006.0906-7590.04675.x Graz FP (2004). The behaviour of the species mingling index Msp in relation to species dominance and dispersion. European Journal of Forest Research 123: 87-92. - doi: 10.1007/s10342004-0016-8

Hui G, Gadow KV (2003). Quantitative analysis of forest spatial structure. China Science and Technology Press, Beijing, China, pp. 27-62.

Hui G, Gadow KV, Zhao Z, Hu Y, Xu H, Li Y, Zhang L, Zhang G, Liu W, Yuan S (2016). Principles of structure-based forest management. China Forestry Publishing House, Beijing, China. pp. 23102.

Janda P, Svoboda M, Bače R, Cada V, Peck JE (2014). Three hundred years of spatio-temporal development in a primary mountain Norway spruce stand in the Bohemian Forest, central Europe. Forest Ecology and Management 330: 304-311. - doi: 10.1016/j.foreco.2014.06.041

Janík D, Adam D, Hort L, Král K, Ašamonil P, Unar P, Vrška T (2014). Tree spatial patterns of Abies alba and Fagus sylvatica in the Western Carpathians over 30 years. European Journal of Forest Research 133: 1015-1028. - doi: 10.1007/s103 42-014-0819-1
Kint V (2005). Structural development in ageing temperate Scots pine stands. Forest Ecology and Management 214: 237-250. - doi: 10.1016/j. foreco.2005.04.014

Kint V, Lust N, Ferris R, Olsthoorn AFM (2000). Quantification of forest stand structure applied to Scots pine (Pinus sylvestris L.) forests. Investigación Agraria: Sistemas y Recursos Forestales, Fuera de serie 1: 147-163. [online] URL: http://revistas.inia.es/index.php/fs/article/view/ 681

Kint V, Meirvenne MV, Nachtergale L, Geuden G, Lust N (2003). Spatial methods for quantifying forest stand structure development: a comparison between nearest-neighbor indices and variogram analysis. Forest Science 49: 36-49. [online] URL: http://www.ingentaconnect.com/con tent/saf/fs/2003/00000049/00000001/art00003 Knoke T, Seifert T (2008). Integrating selected ecological effects of mixed European beechNorway spruce stands in bioeconomic modeling. Ecological Modeling 210: 487-498. - doi: 10.1016/j.ecolmodel.2007.08.011

Kuuluvainen $\mathrm{T}$, Wallenius $\mathrm{TH}$, Kauhanen $\mathrm{H}$, Aakala T, Mikkola K, Demidova N, Ogibin B (2014). Episodic, patchy disturbances characterize an old-growth Picea abies dominated forest landscape in northeastern Europe. Forest Ecology and Management 320: 96-103. - doi: 10.1016/j. foreco.2014.02.024

Li Z, Wang X (1981). The distribution of Pinus yunanensis var. tenuifolia in relation to the environmental conditions. Acta Phytoecologica et Geobotanica Sinica 5: 28-37.

Li J (2008). Study on the quantitative analysis of the oak natural secondary forest in Baotianman nature reserve. Master thesis, Henan Agriculture University, Zhengzhou, Henan, China, pp. 52-66.

Li Y, Hui G, Zhao Z, Hu Y (2012). The bivariate distribution characteristics of spatial structure in natural Korean pine broad-leaved forest. Journal of Vegetation Science 23: 1180-1190. - doi: 10.1111/j.1654-1103.2012.01431.x

Li Y, Hui G, Zhao Z, Hu Y, Ye S (2014a). Spatial structural characteristics of three hardwood species in Korean pine broad-leaved forest - validating the bivariate distribution of structural parameters from the point of tree population. Forest Ecology and Management 314: 17-25. doi: 10.1016/j.foreco.2013.11.012

Li Y, Ye S, Hui G, Hu Y, Zhao Z (2014b). Spatial structure of timber harvested according to structure-based forest management. Forest Ecology and Management 322: 106-116. - doi: 10.1016/j.foreco.2014.02.042

Li Y, Wang L, Yu S, Ye S, Lu D (2016). Spatial structure of Syzygium hancei community along coastline of Guangxi. Chinese Journal of Ecology 35: 726-732. [online] URL: http://en.cnki. com.cn/Article_en/CJFDTOTAL-STXZ20160302 2.htm

Muscolo A, Bagnato S, Sidari M, Mercurio R (2014). A review of the roles of forest canopy gaps. Journal of Forestry Research 25: 725-736. - doi: 10.1007/s11676-014-0521-7

Ni R, Baiketuerhan Y, Zhang C, Zhao X, Gadow KV (2014). Analysing structural diversity in two temperate forests in northeastern China. Forest Ecology and Management 316: 139-147. doi: 10.1016/j.foreco.2013.10.012 
Peck JE, Zenner EK, Brang P, Zingg A (2014). Tree size distribution and abundance explain structural complexity differentially within stands of even-aged and uneven-aged structure types. European Journal of Forest Research 133: 335346. - doi: 10.1007/s10342-013-0765-3

Petritan IC, Commarmo B, Hobi ML, Petritan AM, Bigler C, Abrudan IV, Rigling A (2015). Structural patterns of beech and silver fir suggest stability and resilience of the virgin forest Sinca in the Southern Carpathians, Romania. Forest Ecology and Management 356: 184-195. - doi: 10.101 6/j.foreco.2015.07.015

Pommerening A (2002). Approaches to quantifying forest structures. Forestry 75: 305-324. - doi: 10.1093/forestry/75.3.305

Pommerening A (2006). Evaluating structural indices by reversing forest structural analysis. Forest Ecology and Management 224: 266-277. doi: 10.1016/j.foreco.2005.12.039

Pommerening A, Stoyan D (2006). Edge-correction needs in estimating indices of spatial forest structure. Canadian Journal of Forest Research 36 (7): 1723-1739. - doi: 10.1139/xo6-060 Potvin C, Dutilleul P (2009). Neighborhood effects and size asymmetric competition in a tree plantation varying in diversity. Ecology 90: 321327. - doi: 10.1890/08-0353.1

Sheng Z, Xie S, Pan C (2010). Probability and mathematical statistics. Higher Education Press, Beijing, China, pp. 30-120.

Silver EJ, D'Amato AW, Fraver S, Palik BJ, Bradford JB (2013). Structure and development of old-growth, unmanaged second-growth, and extended rotation Pinus resinosa forests in Minnesota, USA. Forest Ecology and Management
291: 110-118. - doi: 10.1016/j.foreco.2012.11.033 Spies TA (1998). Forest structure: a key to the ecosystem. Northwest Science 72: 34-36.

Svebsson JS, Jeglum JK (2001). Structure and dynamics of an undisturbed old-growth Norway spruce forest on rising Bothnian coastline. Forest Ecology and Management 151: 67-79. doi: 10.1016/S0378-1127(00)00697-6

Takashi K, Mitsuishi D, Uemura S, Suzuki Jl, Hara $\mathrm{T}$ (2003). Stand structure and dynamics during a 16-year period in a sub-boreal conifer-hardwood mixed forest, northern Japan. Forest Ecology and Management 174: 39-50. - doi: 10.1016/S0378-1127(02)00018-X

Tuten MC, Meador AS, Fulé PZ (2015). Ecological restoration and fine-scale forest structure regulation in southern ponderosa pine forests. Forest Ecology and Management 348: 57-67. - doi: 10.1016/j.foreco.2015.03.032

Vilhar U, Simončič P (2012). Water status and drought stress in experimental gaps in manager and semi-natural silver fir-beech forests. European Journal of Forest Research 131: 13811397. - doi: 10.1007/s10342-012-0605-X

Wang X (1991). The phytocoenological features of Pinus yunnanensis var. tenuifolia forest in Guangxi. Bulletin of Botanical Research 11: 91103.

Wehenkel C, Brazão-Protázio JM, Carrillo-Parra A, Martínez-Guerrero JH, Crecente-Campo F (2015). Spatial distribution patterns in the very rare and species-rich Picea chihuahuana tree community (Mexico). PloS ONE 10: e0140442. doi: 10.1371/journal.pone.0140442

Yang B, Li D (1988). The fertility characteristics of soil in the distribution area of Pinus yunna- nensis var. tenuifolia in Yachang, Guangxi. Journal of Guangxi Agricultural College 7: 27-33.

Zhao Z, Hui G, Yuan S, Liu W, Wang R (2009). Spatial structure characteristics of Quercus aliena var. acuteserrata natural forest in Xiaolongshan. Scientia Silvae Sinicae 45: 1-6.

\section{Supplementary Material}

Fig. S1 - Pearson's correlation coefficient for $M$ in the $M-U$ joint distribution.

Fig. S2 - Spearman's rank correlation coefficient for dominance $(U)$ in the $M-U$ joint distribution.

Fig. S3 - Spearman's rank correlation coefficient for mingling $(M)$ in the $M-W$ joint distribution.

Fig. S4 - Spearman's rank correlation coefficient for uniform angle index $(W)$ in the $M$ $W$ joint distribution.

Fig. S5 - Spearman's rank correlation coefficient of dominance $(U)$ in the $U-W$ joint distribution.

Fig. S6 - Spearman's rank correlation coefficient of uniform angle index $(W)$ in the $U$ $W$ joint distribution.

Box 1 - R code for calculating the four nearest-neighbor structure indices.

Link: Li_2405@supploo1.pdf 